\title{
Wind Power Turbine and Its Aerodynamic Characteristics
}

\author{
Xianyi Qian ${ }^{\mathrm{a}}$, Yiming $\mathrm{He}^{\mathrm{b}}$ \\ ${ }^{a}$ School of Electronic Information \& Electric Engineering, Changzhou Institute of Technology, \\ CZU,Changzhou, China \\ ${ }^{b}$ Changzhou Institute of Technology, CZU, Changzhou, China
}

\begin{abstract}
We have mainly studied wind power turbine's aerodynamic characteristics in this paper. We first introduced the types of wind power turbines, and then analyzed the force on the vanes which caused by air flow. We also studied the geometry shape of vanes' type and its aerodynamic characteristics. At last, we concluded the corresponding formulas about wind power turbine's aerodynamic characteristics. All what we have studied have important role to design wind power turbine's vanes.
\end{abstract}

Index Terms: Wind Turbine; Types of Vanes; Vane's Aerodynamic Characteristics

(C) 2012 Published by MECS Publisher. Selection and/or peer review under responsibility of the International Conference on E-Business System and Education Technology

\section{Introduction}

Wind power turbine has been developed about 100 years, now there are many kinds of types. The old type hasn't been used any more. Modern wind power turbines are being used by many countries. And some newtype wind turbines are being developed. Although there all kinds of wind turbines, their principles are almost same, which acquiring energy by means of wind wheel and then being converted into other forms of energy.[1]

\section{Wind Power Turbine}

\subsection{Types of wind power turbines}

Although there are all kinds of wind power turbines, they can be divided into two types: Fig.1(a) shows the horizontal axis wind turbine that the wind wheel's rotating axis is parallel to wind direction; Fig.1(b) shows the vertical wind power turbine that wind wheel's rotating axis is vertical to air flow direction.

\footnotetext{
* Corresponding author.

E-mail address: hbxfqxyqxy_123@163.com
} 


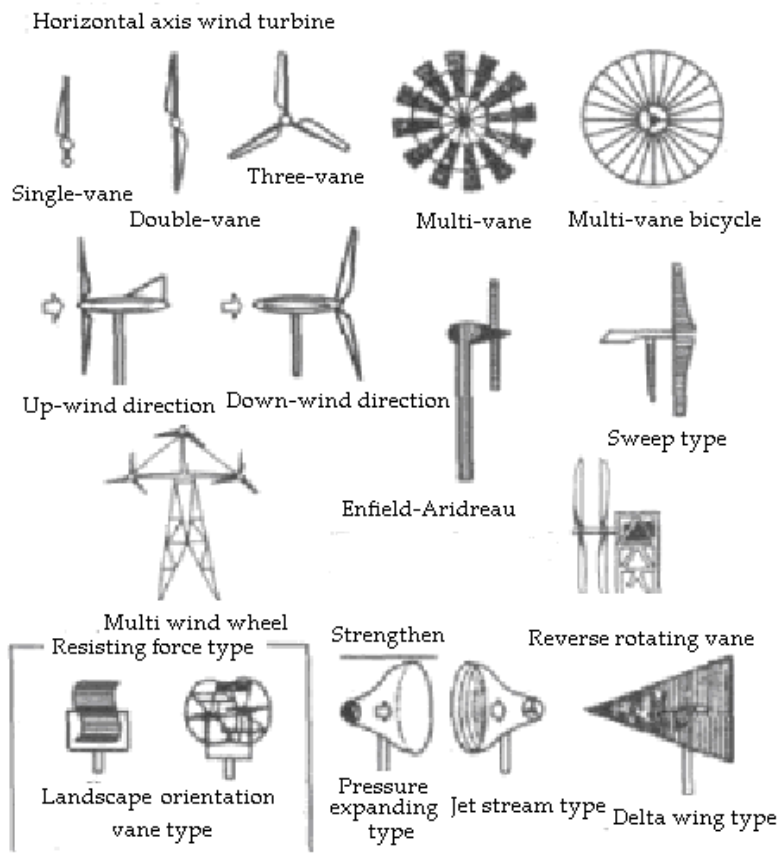

(a) Horizontal axis wind turbine

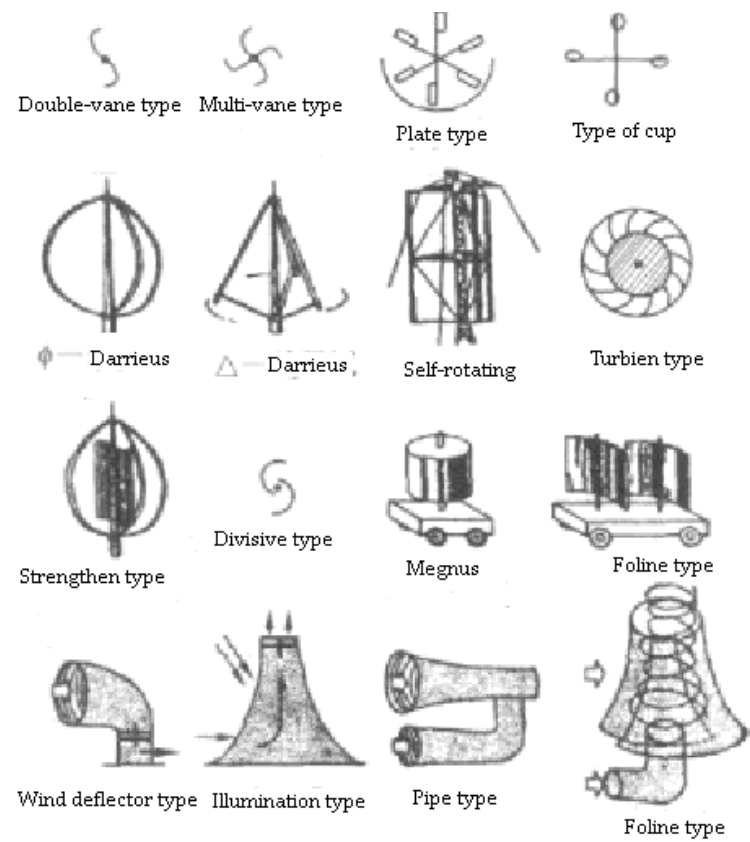

(b) Vertical wind power turbine

Fig. 1. Wind power turbines 
Horizontal axis wind turbine can have two kinds of types: lift force type and resisting force type. Lift force type turbine's rotating speed is very high, and the resisting force type turbine's rotating speed is slow. Most wind power turbines use lift force type horizontal axis wind turbine. And most of them have wind-facing equipment which can rotate with wind direction. To some small type of wind turbines, this kind of windfacing equipment use tail vane. And to some large type of wind turbine, it is realized by means of transmission structure which consists of wind direction sensor and servo electromotor. Wind power turbine's wheel which lies in front of tower is called up wind turbine, and the wheel which lies back of the tower is called down wind turbine. Horizontal axis wind turbines have too many styles: some turbines have wind wheel which can rotate conversely; some turbines are fixed many wheels on one tower, which can reduce the cost of tower at the condition of normal output power; some turbines use cone shroud which can centralize or diffuse air flow while it passed the horizontal axis [2].

Vertical wind power turbine: Vertical wind power turbine needn't to face wind direction when it changes, which is a great advantage which relatives to horizontal axis wind power turbine. It not only simplifies the design structure, but also reduces the peg-top force when the wind wheel faces wind direction. There are some kinds of types about vertical wind power turbine which using resisting force. It includes wind wheel which made by flat board and cups, and this is a kind of pure resisting device. It also includes S-type wind turbine which has parts of lifting-force, it is still the resisting force device. All these devices have big starting moment and low tip speed. On the given conditions of wheel size, weight and cost, its output power is low. Darrieustype wind wheel was invented by G.J.M in 1830s. In 1970s, Canada scientists studied this kind of invention. Now, it is the main competitive type of horizontal axis wind turbine. Darrieus-type wind wheel a kind of lifting-force device, whose section of bending vane is aerofoil. Its starting moment is very low, but its tipspeed ratio can be very high. For the same given wind wheel's weight and cost, its output power is very high.

Today, there are many kinds of Darrieus -type wind turbines, such as $\Phi$-type, $\Delta_{\text {-type and Y-type. These }}$ wind wheels can be designed single-vane, double-vane, three-vane or multi-vane. In China, we usually use three-vane type wind wheel. There are some others forms of vertical axis wind wheels, such as Mark.Lawes effect wind wheel which constructed by self-rotating cylinder. When it operates in air flow, the produced moving locomotivity is caused by Mark.Lawes effect, and it is proportional to wind speed. Some kinds of vertical wind wheels use pipe or vortex generator tower to increase speed by using pressure-expander to change horizontal air flow into vertical direction. And some vertical wind wheels realize this by means of sun energy or some materials' combustion.

\subsection{Wind power turbine's aerodynamic basis}

Wind power turbine mainly uses the wind wheel which used to lift air flow. The air flow's lifting-force is a kind of force which caused by aerocraft's aerofoil and Fig. 2 shows this. When the air flow on aerofoil has any change, there is a low-pressure area will be on the surface of aerofoil, and a high-pressure area will be under aerofoil. So a resultant force will be produced, and it is vertical to air flow direction. Fig. 3 shows the force. Of course, the resisting force will also be produced, which can reduce wind speed.

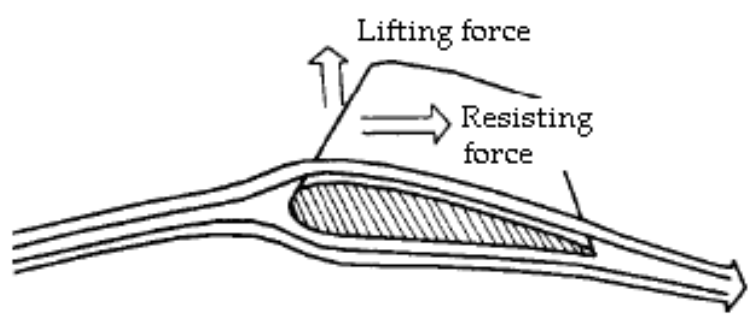

Fig. 2. Lifting force of air flow 


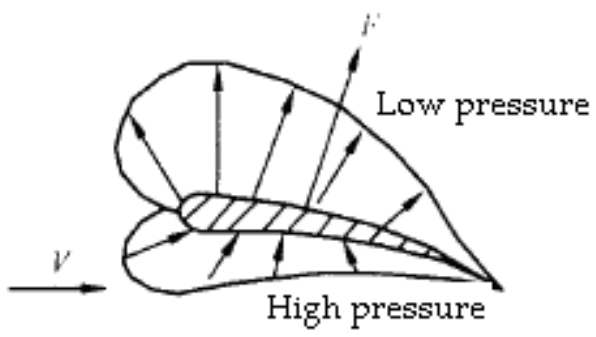

Fig. 3. High pressure area

We can spread a piece of board from a moving car, the end of board in air is called front border. We can feel a lifting force when we lift the front border; and we can feel a down force when press the front border. There is an angle between up-force and down-force, which is called zero lift angle.

When is in the zero lift angel, it will produce a small resisting force. The resisting force will pull the board, which produce 90 degree. The resisting force increases during the process. If the car running speed is very high, the board could be lost from the hands.[3]

Usually, the lift force and resisting force occurs at the same time, if we rotate the front board from zero lift angle to up slowly, the lift force and the resisting force will all increase, and the lift force's increasing speed is higher than resisting force. If the angle is equal to a certain value, the lift force will reduce suddenly, and the resisting force will increase continuously. At this time, the load angle is about 20 degree, and the tested board will be stall.

For some certain load angels, the lift force is bigger than resisting force, and the lift force is the power which used to design high efficient wind turbine. The high lift force area and the low resisting force area on vane are very important. Fig. 4 shows the vane's lift force and resisting force's curve.

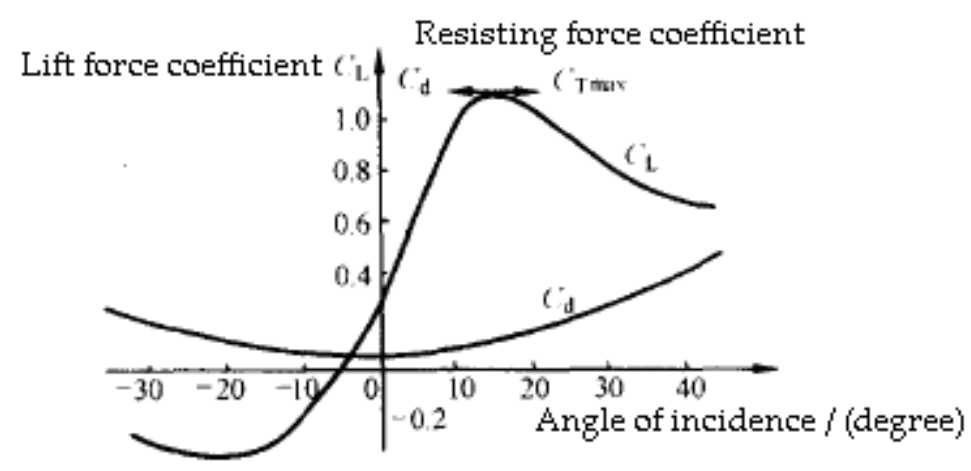

Fig. 4. Curve of vane's lift force and resisting force

Fig.1 (b) shows the Darrieus-type vertical wind power turbine whose power axis is vertical to wind direction. Sail boat can be moved in accordance with circulatory motion, and the sail will be forced on one surface, and it will be bent. When the sail bending angle reach one certain value, the other surface of sail will be forced. The Darrieus-type vertical wind power turbine has the similar principle with this. [4]

To horizontal wind power turbine, the lift force always makes the vanes rotate. If the wind speed is a constant, the lift force is a constant, too. The lift force varies during the process of Darrieus-type vertical wind power turbine vanes' rotating. The lift force between two areas is always small during the process of vanes' rotating. And the other area's lift forces will be bigger during the process of vanes' rotating. 


\section{Wind Power Turbine's Aerodynamic Characteristics}

\subsection{Wind power turbine's aerodynamic basis}

The wind wheel of wind power turbine usually consists of two or three vanes. The function of vanes is converting wind energy into mechanical energy. Fig.5 shows the section shape of modern wind power turbine's vane.

We first consider the fixed vane. The wind speed is vector ${ }^{U}$, and its direction is in parallel with vane's surface. The vane's geometry shape has been defined here: the end point of vane is called back border and the A point on the circular point. And the length between $A B$ points is one before connection, which is called vane chord. AMB is called up surface, and ANB is called down surface of vane. The bending broken line from front border to back border is called midline of vane. The attack angle $l$ is the angle between vane chord and air flow speed vector $v$.

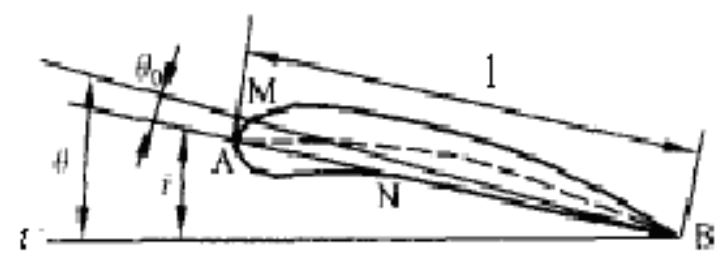

Fig. 5. Wind power turbine's vane type

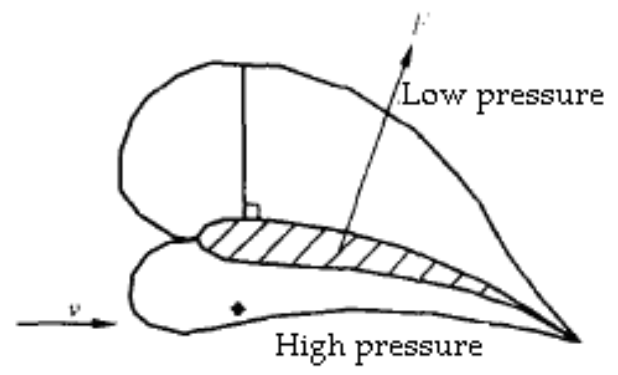

Fig. 6. Distribution of vane's pressure

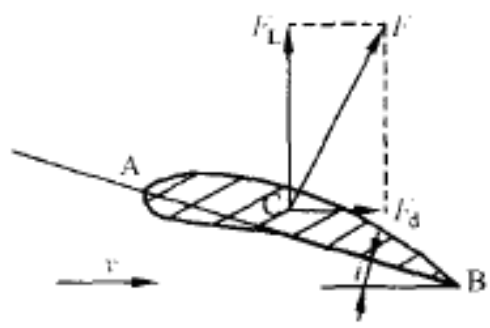

Fig. 7. Stressed vane surface 
The resultant force $\mathrm{F}$ can be represented by the following equation:

$$
F=\frac{1}{2} \rho C S v^{2}
$$

The force $\mathrm{F}$ can be divided into two component forces: one is the lift force $\mathrm{F}_{1}$ which is vertical air flow speed $U$; the other is the resisting force $\mathrm{F}_{\mathrm{L}}$ which is in parallel with air flow speed $v . \mathrm{F}_{\mathrm{L}}$ and $\mathrm{F}_{1}$ can be represented by the following equations:

$$
\begin{aligned}
& \mathrm{F}_{\mathrm{L}}=\frac{1}{2} \rho C_{L} S v^{2} \\
& F d=\frac{1}{2} \rho C_{d} S v^{2}
\end{aligned}
$$

The CL and Cd in equations (2) are vane's lift force coefficient and resisting coefficient respectively. Because F1 is vertical to FL, we can get the following equation:

$$
F_{2}=F_{L}^{2}+F_{d}^{2}
$$

Fig.8 and Fig.9 shows the changing curve of vane's lift force coefficient $C_{L}$ and resisting force coefficient $\mathrm{C}_{\mathrm{d}}$.

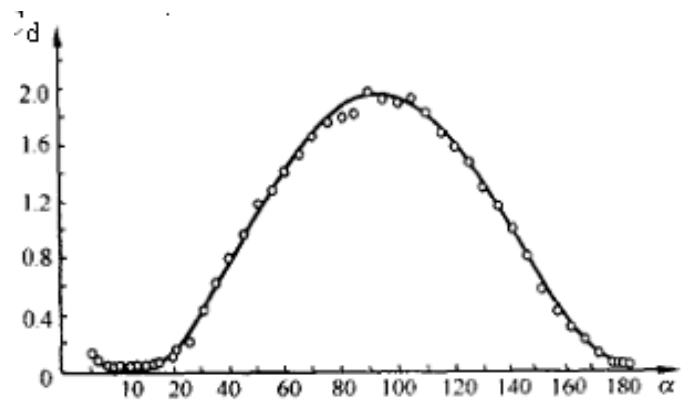

Fig. 8. Aerofoil $\mathrm{C}_{\mathrm{d}^{-}} \alpha$ curve

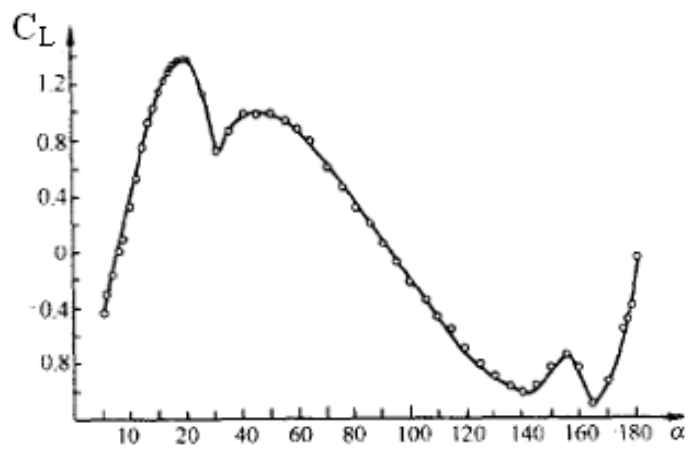

Fig. 9. Aerofoil $\mathrm{C}_{\mathrm{L}^{-}} \alpha$ curve 


\subsection{Wind wheel's aerodynamic characteristics}

- Wind wheel axis: the axes when wind wheel rotates.

- Rotating plane: the plane when vane rotates, which is vertical to wind wheel axis.

- Wind wheel diameter: the diameter of wind wheel rotating circle.

- Vane axis: it is vane portrait axis, and the rotating angle which is relative to rotating plane can be changed by rotating the vane axis.

- Vane section: the section which is intersected between column and vane whose radius is $r$.

- Fixing angle or pitch angle: Fig.10 shows the angle $\alpha$ which is between rotating plane and aerofoil chord which is in the location of radius r.[6]
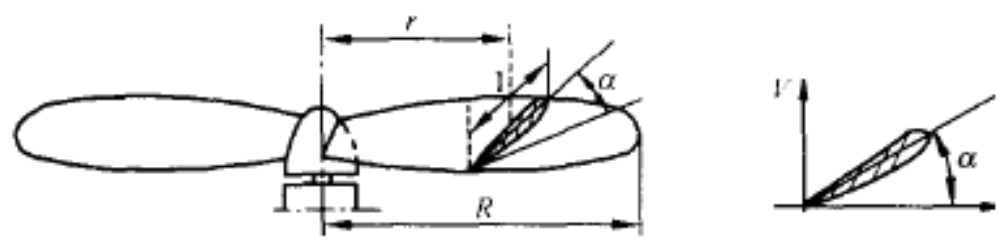

Fig. 10. Wind wheel aerodynamic geometry terms

\subsection{Characteristics of foline}

A basic cell which lies on the radius of wind wheel vane is called foline whose chord length is equal to one and fixing angle is $\alpha$. This foline's speed is $|\nu|=2 \pi r n$ in rotating plane. Fig.11 shows the speed $\omega$, if we consider $v$ into the axial air speed when it flows into wind wheel.

$$
\begin{array}{ll}
\vec{v}=\vec{u}+\vec{\omega} & i=I-\alpha \\
\vec{V}=\vec{u}+\vec{w} & \vec{w}=\vec{v}+\vec{u}
\end{array}
$$
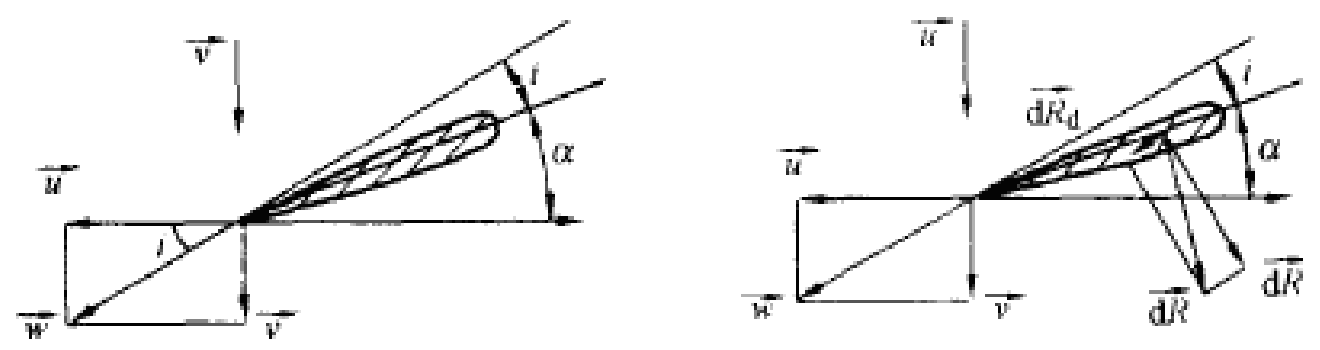

Fig. 11. Relationship between aerofoil parameters

The angle I is called angle of inclination between $\omega$ and wind wheel rotating plane.

Because of relative air flow $\vec{w}$, the foline will produces a air motive force $\mathrm{dR}$ which can be divided into 
two forces: one force is lift force dRL which is vertical to $\vec{w}$, another force is resisting force $\mathrm{dRr}$ which is in parallel to $\vec{w}$. With the variation of radius of $\mathrm{r}$, the values of CL and Cd are also related to attack angle.[7]

The air motive force $\mathrm{dR}$ makes wind wheel produce axial thrust and torque which drive wind wheel.

The component force $\mathrm{dF}$ comes from $\mathrm{dR}$ in rotating plane. And $\mathrm{dM}$ is the torque of wind wheel axis. The calculation equations of $\mathrm{dF}$ and $\mathrm{dM}$ are:

$$
\begin{aligned}
& d F=d R_{L} \cos I+d R_{d} \sin \\
& d M=r\left(d R_{L} \sin I-d R_{d} \cos I\right)
\end{aligned}
$$

\section{Conclusions}

The research reveals multi-media resources, used as teaching resources, provide teachers and students massive authentic meaningful language input and facilitate teacher-student and student-student interaction. Students being the center of learning, the theme-oriented English teaching mode can arouse students' interests in English learning, develop their autonomous learning ability, cultivate their sentiment and improve their practical language ability.

\section{References}

[1] ZHANG Guoxin, Parallel-in technology of wind power and power quality control strategy[J], ELECTRIC POWER AUTOMATION EQUIPMENT, 2009 29(6) .

[2] Lin Yonggang, Semi-physical Simulation Test-bed for Electro-hydraulic Proportional Pitch-controlled Wind Turbine System[J], CHINA MECHANICAL ENGINEERING, 2005 16(8) .

[3] Li Wenhua, Analysis of pneumatic character of airfoil for wind turbine system[J], GENERAL MACHINERY, 2006(11) .

[4] Jin Xin, Coupled Vibration Analysis of Wind Turbine[J], CHINA MECHANICAL ENGINEERING, 2008 19(1).

[5] Tian Yaping, Design and Analysis on the Variable Propeller Pitch Mechanism of MW Wind TurbineGenerator[J],TRANSACTIONS OF SHENYANG LIGONG UNIVERSITY, 2005 24(4).

[6] Li Dongdong, WIND SPEED MODEL FOR DYNAMIC SIMULATION OF WIND POWER GENERATION SYSTEM[J], PROCEEDINGS OF THE CHINESE SOCIETY FOR ELECTRICAL ENGINEERING, 2005 25(21) .

[7] Liu Fangyu, Dynamic Simulation of Doubiy-fed Wind Power System Based on Matlab [J], ELECTRICAL ENGINEERING, 2007 (11). 